\title{
Improving Schooling Taste and Promoting Quality Development
}

\author{
Zhixiang Deng \\ School of Eudcation, Jianghan University \\ Wuhan 430056, China
}

\begin{abstract}
In order to promote the balanced development of compulsory education, the competent education authority arranged cooperation between several universities and the corresponding primary and middle schools in the entrusted management of school running. For example, after discussion, Jianghan University and Huangling Middle School established five development projects for the purpose of promoting the development of Huangling Middle School. With more than two years' joint efforts, these five projects helped meet the requirements of Wuhan Education Bureau, thanks to both the professionalism and dedication of the team of Jianghan University and the active cooperation of Huangling Middle School. Regrettably, the enthusiasm of the teachers in Huangling Middle School was not fully activated, and such cooperation has no direct benefit to the promotion of the teachers in Jianghan University; therefore, the sustainability of the team was affected, and many ideas of cooperation could not be realized for various reasons.
\end{abstract}

Keywords-Universities and primary and middle schools; Entrusted management; Schooling cooperation

\section{INTRODUCTION}

As arranged by Wuhan Education Bureau, Jianghan University and Huangling Middle School entered into a relationship of entrusted management (schooling cooperation) from 2016 to 2018. Prof. Deng Zhixiang, the project leader of Jianghan University, put forward a guiding ideology of "cultural inheritance and innovation". He pointed out that both sides are equal partners and explorers, and that the team of Jianghan University must, by focusing on its "professionalism" and "research", provide appropriate and professional but not ultra vires guidance as well as professional service mainly on consulting and information. Based on the investigation of the needs of Huangling Middle School and with consideration of the advantages of Jianghan University, the two parties established five projects after repeated communication, namely, "Modernized School Management", "Teachers' Professional Development", "Small Smart Classes", "the Power of Positive Philosophy", and "the Action and Experience of Moral Education". The cooperation was developed from such specific aspects of Huangling Middle School as improved schooling concept, optimized school management, in-depth teaching research, perfected training system, training of backbone teachers, sharing of educational resources, and experiments of educational reform, and Huangling Middle School was satisfied with the work of Jianghan University.

\section{PROCESS}

\section{A. Improved Schooling Concept and Optimized School Management}

Sukhomlinskii, a famous educationist and outstanding middle school principal of the former Soviet Union, said: "In school management, ideological management takes precedence over administration." With particular attention to ideological guidance and theoretical study, the team of Jianghan University led the leaders and teachers of Huangling Middle School to study seriously the modern educational thought. Prof. Deng Zhixiang gave a report on "The Thinking of Teachers' Development and Management" for the whole school, aiming to help the school upgrade its schooling concept, define its educational thinking, standardize its educational behavior and activate its educational vitality. $\mathrm{He}$ encouraged the school to take students' healthy growth as its supreme pursuit of work and as the starting point and objectives of all school work, and to run school seriously, quietly, and effectively without deliberate pursuit of "reputation" and "honor" or more so "reputation" and "honor" that do not conform to the rules of education.

Huangling Middle School retained the tradition of "family culture", which formed a gap from modern school management. With the help of the team of the School of Education of Jianghan University, Huangling Middle School mainly revised three of its systems (for the positions, employment and distribution of its teaching and administrative staff). A trial run in 2017 proved its obvious benefits in activating the enthusiasm of teachers and bringing well-ordered arrangement of the school work. Especially in this semester, an appointment system of two-way selection is first applied to the middle management of the school, and in view of the current work efficiency, the new management of the school has got a clear division of work and is widely recognized by the teachers for its initiative, creation and innovation. In future, further reforms will be carried out. To be specific, every teacher will participate in the school management to achieve a close matching between each staff member and his/her duties and responsibilities, and more improvements will be made to realize a modern school management system. 


\section{B. Learning Information Technology and Teachers' Professional Development}

Information technology has a revolutionary impact on the development of education, and will become a key factor to change the way of learning and to improve the quality of teaching. The construction of smart campus and smart classes has become a major trend of educational development. Jianghan University, relying on its teachers and equipment of educational technology, helped Huangling Middle School successfully declare a municipal project of "the Exploration and Practice of the Teaching Model of Small Smart Classes", which also means a promotion of "Smart Classes". In 2016, the average age of teachers in Huangling Middle School was 46 years old, and no new teachers had been employed for 13 years, which indicated a serious structural problem. In order to improve the professionalism of the school and realize a true urbanization of rural education, it was imperative to promote the professional development of existing teachers. Therefore, the project of "Teachers' Professional Development" was established to guide the teachers of Huangling Middle School to change their educational concepts, where an action "gas station" was set up accordingly.

We integrated the project of "Small Smart Classes" with the project of "Teachers' Professional Development" to propel the teachers' professional development by use of information technology.

\section{1) Teacher Training}

During the progress of the two projects, we highlighted the theoretical guidance and the importance of learning. Teachers must be trained before taking up their teaching work. The lectures of "Teachers' Moral Cultivation and Happiness" given by Prof. Liu Pingxiu, a senior expert of moral education, and "Close to the Classes of American Primary and Middle Schools" by Dr. Li Xing, a doctor who received study in the United States, broadened teachers' horizons. Moreover, through the report of "the Research on the Design and Application of APT-Model-Based iPad Electronic Teaching Materials Used in Smart Classes" by Professor Zhang Yi, a top expert in the field of educational informatization, the teachers better understood that e-schoolbags are not only a good assistant to teachers but also a good teacher for students, and vividly experienced the effectiveness of e-schoolbags in subject teaching. The traditional way of teaching by using a chalk and a book only is subject to change with more new elements infused. Theory is accompanied by practice. Between January 19-20, 2017, all the teachers of the school went to the laboratories of Jianghan University to make micro-lessons, audios and video clips.

\section{2) Smart Classes}

The development of research projects was energetically supported to promote the teaching quality. The two parties determined through communication the ideas of cooperation in the project implementation of "Small Smart Classes". Teacher Ai Di worked out the specific plan and the implementation schedule. Then Dr. Li Xing guided the teaching design and implementation of smart classes, specifying the procedures and rules thereof. According to the implementation plan, from April to June 2017, eight teachers of Chinese, Mathematics,
English and Physics took the lead in piloting smart classes, where the team of Jianghan University provided group and individual guidance to the teaching design and class videos. A series of practical training in smart classes raised the teachers' enthusiasm for teaching reform and also improved their level of information technology. The teachers of Jianghan University participated many times in the preparation of smart classes and commented on all the videos of open classes in the open smart class month. In Wuhan's joint demonstration activity of small classes in 2017, the classes demonstrated by the two teachers of Huangling Middle School won the unanimous praise from the leaders and teachers of the city and districts.

\section{3) Guidance of Teaching and Scientific Research}

The teaching research focused on two basic disciplines, namely Chinese and mathematics. Both of the two experts Pan Jiaming and $\mathrm{Wu}$ Xiujun have the teaching experience in key middle schools and respectively study and teach in Jianghan University the Teaching Methodology of Middle School Chinese and the Teaching Methodology of Middle School Mathematics. They brought freshness to the teaching research of Huangling Middle School. The team of Jianghan University also led the teachers of Huangling Middle School to participate in the teaching research activities of Cuiwei Middle School, Qiyi Middle School, and the junior section of Foreign Languages School, where everyone benefited a lot. With regard to the scientific research, Prof. Deng Zhixiang and Dr. $\mathrm{Xu}$ Qiu popularized the knowledge of educational research. Teacher Ai Di was then responsible for the project of "the Exploration and Practice of the Teaching Model of Small Smart Classes", and Prof. Deng Zhixiang, Prof. Chen Huijun and Prof. Liu Pingxiu mainly guided the scientific research of Teachers Li Lianglin, Jiang Taiheng, Cheng Ling and Li Xujun. The "Exploration and Practice of the Teaching Model of Small Smart Classes" was rated "Excellent" by the relevant experts both in the courses of opening and mid-term examination. The theses written by $\mathrm{Li}$ Lianglin and Jiang Taiheng were published respectively in Issues 8 and 9 of "New Curriculum Research" of 2018. Li Xujun's thesis won the first prize of theses of Hubei Provincial Academy of Moral Education in 2017. Zhu Lingzhi's thesis won the second prize of theses of Hubei Provincial Academy of Moral Education, and her personal project of moral education at the district level was successfully established.

\section{Distinctive School Characteristics and Optimized School Culture}

\section{1) Mental Health and Formation of Characteristics}

Differences and characteristics are the indispensable elements for the lively development of basic education. The School of Education of Jianghan University, based on its own advantageous and featured discipline - Mental Health Education and in the light of the actual situation of Huangling Middle School, decided to establish Huangling Middle School into a school featuring mental health education. The program, with the theme of positive psychology, mainly involved the establishment of psychological archives for all students, the progressive organization of group activities and lectures for teachers, students and parents, and targeted psychological counseling, so as to arouse students' self-esteem and stimulate 
their self-confidence and to help students pursue a beautiful life and academic improvements with positive attitude and positive actions and possess a higher level of mental health and a more healthy and positive ego. With the joint efforts of Prof. Chen Huijun and the school, Huangling Middle School successfully passed in June 2018 the appraisal and election at the "Psychological Summit Forum of Six Provinces in Central China", and was awarded the medal and commendation for "A School Featuring Mental Health".

\section{2) Autonomous Moral Education and Achievements Thereof \\ Jianghan University designed and implemented the "1357} Program" of "autonomous moral education" in the light of the actual situation of students and teachers in Huangling Middle School. The goal of "autonomous moral education" was ego and quality improvement. Featuring autonomous, experiential and developmental education, the program consisted of five parts, namely autonomous cognition, planning, experience, regulation and improvement, and was operated through seven channels, namely: campus culture - an invisible way to practice "autonomous moral education"; classroom teaching a main channel for practicing "autonomous moral education"; class and league construction - the grass-roots position for practicing "autonomous moral education"; activity practice an effective way for practicing "autonomous moral education", psychological counseling - the demands of the time for practicing "autonomous moral education"; habit training- the foundation for practicing "autonomous moral education"; home and school cooperation - a source of joint forces for practicing "autonomous moral education". The influences of "autonomous moral education" not only affected moral education, but also extended to class teaching and social life, and thus students benefited from it a lot in all aspects.

Under the guidance of Prof. Liu Pingxiu, great achievements were made in the active participation, experiencing and understanding of "autonomous moral education". Jianghan University arranged various activities together with the students of Huangling Middle School, such as holding a large theme class meeting of "My Youth", a poetry reading activity of "Youth and Dreams", and a large reading activity of "Passion Burning Years" for teachers and students, which were a pledge of youth and a positive guide; visiting practice bases; organizing fire, air defense and evacuation drills; carrying out etiquette and legal education on positive behaviors; beautifying the environment and expanding spaces jointly by home and school; visiting the elderly at the Double Ninth Festival and creating a brand; organizing a talent show at the Art Festival. A "Moral Wall" was created on the exterior wall of every classroom for praising excellent students. The Student Union conferred the flowing red flags for "Compliant Class" and "Cleanest Class" at the flag-raising ceremony every Monday.

\section{3) Colorful School Culture}

The team of Jianghan University took its advantage as a comprehensive university to recommend and provide instructors for the guitar clubs, dance clubs, football clubs and other student associations of Huangling Middle School. Prof. Liu Pingxiu also led the university students to guide and participate in the Sports And Arts Festival of the school.

All activities were close to the times, the life, and the students, with an integration of school culture and ideological education. They were novel and healthy in contents, well-ordered and elegant in styles, and rich and diversified in forms, and educated students during entertainment. They focused on culture, infusing school culture into teaching activities.

\section{CONCLUSION}

(1) Achievement. With more than two years' joint efforts and through five projects, Jianghan University has met the requirements of Wuhan Education Bureau on its support to Huangling Middle School.

(3) Experience. The achievement is both due to the professionalism and dedication of the team of Jianghan University and the active cooperation of Huangling Middle School.

(3) Regret. The enthusiasm of the teachers in Huangling Middle School was not fully activated, and also such cooperation was of no direct benefit to the promotion of the teachers in Jianghan University; therefore, the sustainability of the team was affected, and many ideas of cooperation could not be realized for various reasons.

\section{REFERENCES}

[1] Wu Honglin, Interscholastic Communities of Primary and Middle Schools under "U-S" Cooperation: Power, Connotation and Operation Strategies, [J]. Exploring Education Development, 2009, (18): 29 31.

[2] Yang Hui, Zhu Huaixin, Analysis on Education Strategies of British Teachers - Based on An Understanding of the Partnership between Universities and Primary and Middle Schools, [J]. Global Education Outlook, 2005, (3): $45 \sim 46$.

[3] Liu Xincheng, Meng Fanhua, Ning Hong, Kang Liying, and Zhang Jingbin, Establishing Cooperative Communities and Building A Practice-Oriented Teacher Education Model, [Z]. Beijing: Capital Normal University, 2009.

[4] Chen Qibiao, Research on the Partnership between Universities and Primary and Middle Schools of Western Countries, [J]. Education Review, 2009 (3):165 -168.

[5] Chen Xiangming, Practical Knowledge: The Knowledge Base of Teachers' Professional Development, [J]. Peking University Education Review, 2003 (1):104 -112. 